\title{
Institutional Stimulation of Deliberative Decision-Making: Division of Labour, Deliberative Legitimacy and Technical Regulation in the European Single Market
}

\author{
THOMAS GEHRING \\ University of Bamberg \\ MICHAEL KERLER \\ University of Bamberg
}

\begin{abstract}
Institutions stimulate deliberative decision-making if they hinder stakeholders from introducing bargaining power into the decision process. This article explores the conditions for, and limits of, the creation of deliberative legitimacy in single market regulation. An assessment of the standardization procedure demonstrates that legitimacy arises only from the combination of political and technical deliberation.
\end{abstract}

\section{Introduction}

It is widely agreed that the European Union suffers from a severe democratic deficit (Follesdal and Hix, 2006; Kohler-Koch and Rittberger, 2007). Public participation and control through elections is still grossly underdeveloped. Parliamentary influence and the government-opposition nexus are much weaker than in domestic political systems (Hix et al., 2005). Unfortunately, adjustment of these deficits might imply a de facto transformation of the current post-national entity into a European federal state.

The democratic deficit assumption is challenged by the literature on deliberation and on regulation. It is increasingly argued that new modes of governance stimulate deliberation among decision-makers and/or within the wider public. Deliberation creates a specific form of non-majoritarian legitimacy that is based on persuasion and the exchange of convincing arguments (Habermas, 1998; Risse, 2000). It may provide a mechanism to democratize 
the European polity short of its transformation into a regular democratic state (De la Porte and Nanz, 2004; Murphy, 2005). From a different angle, Moravcsik (2002) observes that the EU fulfils functions which are usually performed by administrations even in domestic political systems. And Majone (2001; 1996, pp. 15-19) emphasizes that regulation, i.e. the primary task of the EU, ought not to become subject to majoritarian decision-making or bargaining, because regulation is about identifying problem-adequate ('efficient') solutions, while majorities or powerful negotiators will, in the first place, pursue their parochial interests. Accordingly, regulatory decisions are best assigned to independent agencies.

The conceptual divide between the regulation and the deliberation perspectives is surprisingly narrow. They jointly emphasize that power-based majoritarian decision-making and accommodation of preferences through bargaining do not create legitimacy for regulatory decisions. Moreover, they assume that options can be appraised according to criteria that are independent from the preferences of powerful majorities or negotiators. Whereas regulation theory focuses on the quality of outputs and searches for procedures that promise such regulation, deliberation provides a procedure that produces not only legitimate, but also particularly well-reasoned decisions. Regulation by way of deliberation may be more acceptable to those political actors of the EU (in particular the Member States and the Parliament) that are only rarely prepared to assign full decision-making powers to independent agencies (Follesdal and Hix, 2006, pp. 551-7; Lord and Beetham, 2001).

While the normative literature lacks an empirical theory of how deliberative ideals might plausibly be institutionalized in the European arena (Lord and Magnette, 2004, pp. 195-6), authors have begun to explore how realworld actors within the European polity can be effectively induced to adopt binding decisions through deliberation. This means identifying institutionalized opportunity structures that drive actors systematically toward deliberation, while discouraging power-based voting or bargaining. Joerges and Neyer (1997) claimed that comitology committees transform 'intergovernmental bargaining to deliberative political processes' (recently restated by Joerges, 2006). Some observers identify the European Parliament and the Constitutional Convention as institutional arrangements that stimulate deliberation (Eriksen and Fossum, 2002). It has even been argued that the entire EU polity has developed into a 'heterarchy' (Neyer, 2003, pp. 688-90), in which decisions are jointly made by different centres of power so that the bodies involved must persuade each other of their views in order to produce jointly accepted decisions. This theoretical debate still almost entirely lacks an empirical foundation. 
In the following, we offer the blueprint of an institutional arrangement that promises to stimulate deliberative decision-making, thereby producing legitimate and problem-adequate regulatory decisions. It relies on the systematic separation of decision functions and their assignment to different actors. Conventional wisdom has attributed deliberation-conducive effects largely to the skilful design of specific forums, such as committees or the European Parliament. We demonstrate that this perspective doesn't reach far enough, because important incentives for deliberative decision-making emerge from the specific arrangements that divide labour among the decision-making bodies involved. Such arrangements assign important functions to the powerful political actors of the Union, especially the Council and the Parliament, and simultaneously draw on the expertise of other stakeholders and the wider European public. They hinder all actors involved from effectively pursuing their parochial interests. Such arrangements mobilize 'democratic legitimacy' originating from the influence of the Council and the Parliament and at the same time 'technocratic legitimacy' that depends on rational expert deliberation.

We find such an arrangement in several policy areas of single market regulation, but specific conditions must be fulfilled in order to ensure that decision-makers do not resort to their bargaining or voting power to pursue their specific interests. The core idea of the 'New Approach' envisages that the political actors (Commission, Council, and Parliament) define general regulatory standards for larger groups of products or services according to the regular legislative procedures, while more specific rules and case-specific application decisions are assigned to expert bodies embedded within multistep decision procedures. While this form of vertical and horizontal division of labour is increasingly employed for single market regulation, the prototype is the technical regulation of products according to the standardization procedure. Only a careful analysis of regulatory activities elucidates whether deliberative regulation is actually achieved. For this purpose, we compare the regulation of two large product groups, namely machinery and toys. It turns out that standardization under the Machinery Directive fulfils the promises of deliberation entirely, while decision-making under the Toys Safety Directive creates some severe legitimacy gaps. This difference is attributed to the partial failure of the political actors to establish, in the toys case, an effective system of divided labour between the two decision-making levels involved.

\section{Deliberative Decision-Making}

The narrow concept of arguing elucidates the theoretical core of deliberation. It is in contrast to the surprisingly weak concept of deliberation employed by 
most of the literature that focuses on public debate, but it is silent as to the actual influence of deliberation on the final decisions produced. Arguing is diametrically opposed to power-based bargaining and reflects the 'pure' co-ordination logic of deliberation (Neyer, 2003, pp. 690-6).

\section{The Normative Superiority of Deliberation (Arguing) over Bargaining}

Bargaining constitutes the baseline of collective decision-making in negotiations. It is well-known from rational choice theory and reflects strategic action by rational utility maximizers in communicative processes. Despite their common interest in reaching agreement, actors typically have competing interests regarding the distribution of co-operation gains (Scharpf, 1997, pp. 118-24). In order to maximize their return, bargaining actors rely on threats and promises that have to be executed outside the assembly itself. Credibility increases with the attractiveness of an actor's 'best available alternative to agreement'. Accordingly, the outcome of a bargaining process, i.e. the distribution of gains, can be expected to reflect, by and large, the distribution of power among the actors involved (Elster, 1989, pp. 74-82). If decisions may be adopted by a majority, bargaining may stop short of consensus.

Bargaining does not ensure that the most problem-adequate or the collectively most legitimate solutions are identified. Outcomes will improve Paretoefficiency, because they promise some co-operation gains for all involved parties compared to the status quo. However, they may be extremely onesided or problem-inadequate, because they are based upon the status quo and the existing distribution of power among the involved actors. Moreover, any outcome is equally legitimate, because legitimacy rests solely on its voluntary acceptance by the negotiators. Accordingly, legitimacy dwindles as soon as the underlying distribution of power changes significantly.

The communication mode of arguing is diametrically opposed to bargaining. Adapted from Habermasian discourse theory (Habermas, 1984), it is exclusively based on convincing reasons. In an arguing process, competing validity claims are appraised and judged against commonly accepted criteria (Gehring, 2003). Propositions must be accompanied by reasons which refer to commonly accepted criteria. Arguing is a triadic process that involves two separate steps. First, general criteria are collectively identified; second, a specific dispute is explored, and finally decided, in light of these criteria. Hence, convincing reasons are the sole resource in deliberation processes.

Co-ordination in the mode of arguing is more demanding than co-ordination through bargaining. It requires that the participants presuppose an 'ideal speech situation' (Risse, 2000, p. 10). They must abstain from resorting to power resources available outside the negotiations, because 
arguments are simply not convincing if only based on power. In practice, participants must at least assume that the power resources associated with a speaker do not invalidate the arguments that he or she submits. In addition, reasons do not matter unless actors are prepared to question, and possibly revise, their perspectives on the disputed subjects in light of new arguments.

Collective decisions reached by arguing are 'rational' in the Habermasian sense. They are better reasoned, and thus more convincing, than any of the original claims, because they have been collectively examined and approved. Likewise, they are not distorted by the struggle over the allocation of costs and benefits and by the prevailing distribution of power among the participants. The emerging solution is in this regard 'better' than that of decisions emerging from bargaining processes, and it approaches the ideal of 'good governance' (Joerges, 1999; Neyer, 2003, pp. 696-702). It does not matter whether it is in conformity with anybody's parochial interests. This is true also for a discourse on the normative rightness of propositions, because, in such discourses, actors are able to claim convincingly only what is generally acceptable by all those affected if they disregard their parochial interests and stakes. Arguments that are largely rooted in their own parochial interests are not convincing (Eriksen and Weigård, 1997, p. 229).

Remarkably, the legitimacy-creating effect of deliberation (arguing) is not immediately related to transparency of a discourse, or to the participation of all those possibly affected. It suffices that actors can no longer contest the validity of a discursively reached social norm with convincing reasons. Contrary to much of the normatively oriented (Cohen and Sabel, 1997) and some of the analytical literature on the subject (Elster, 1998; Eriksen and Fossum, 2002), arguing may well be employed behind closed doors, for example, by a group of experts. Legitimacy arises from the sincere consideration of all relevant arguments. The whole concept of communicative action would become entirely utopian for political processes if it required general participation of all those possibly affected. Accordingly, Habermas (1998, p. 107) infers from the discourse principle that "just those action norms are valid to which all possibly affected persons could agree as participants in rational discourses' (emphasis added).

\section{Institutional Incentives for Deliberative Problem-Solving}

The theoretical exploration of deliberation-inducing institutional opportunity structures should set out from a conception that does not assume that actors will be prepared to sacrifice the pursuit of their parochial interests if communicative understanding so requires. Unfortunately, deliberation does not elucidate the conditions under which a discourse may become operative 
among real-world actors. Collective decision-making through arguing among real-world actors is widely considered as all too idealistic, if not as entirely utopian, because even powerful actors have to refrain from introducing their power resources into the decision process and have to accept even wellreasoned results that are not (fully) compatible with their parochial interests. Jon Elster (1998) was among the first to point out that rational utility maximizers may, under certain circumstances, resort to an exchange and common appraisal of rational arguments. He suggested that transparency and public observation of political decision processes make it costly, or even impossible, for decision-makers to pursue parochial interests openly that deviate significantly from the common good. In contrast, Habermas (1984, pp. 285-6) and several authors drawing on the theory of communicative action (Risse, 2000) assume that communicative action requires actors not to behave as strategic utility maximizers. Likewise, Joerges and Neyer originally attributed committee deliberation partly to the socialization of committee members (Joerges and Neyer, 1997).

Even simple negotiations, in which the participants make all decisions themselves, provide limited room for deliberative decision-making, but they do not create any institutional incentive to modify interaction in favour of arguing. Discursive interaction among state representatives may contribute to elucidating the circumstances upon which preferences are founded (Risse, 2000). However, assuming that powerful actors would systematically refrain from influencing the choice of regulatory decisions by way of their power resources once circumstances have been clarified, and once preferences have been adjusted accordingly, would be all too altruistic (Elgström and Jönsson, 2000). Hence, simple negotiation processes do not create particular incentives for deliberation.

The separation of specific decision functions may systematically deprive the participating actors of their opportunities to influence the decisionmaking process through bargaining. A discourse comprises two different decision stages, namely the elaboration of general (abstract) criteria and the settlement of disputes in light of these criteria. If these tasks are assigned to different forums, each of these forums will concentrate on a subset of the entire decision load. This relatively simple form of vertical differentiation of a decision process dramatically changes the decision-making rationales of the actors involved at both levels.

Specialization on the elaboration of abstract decision criteria facilitates arguing because it tends to prevent actors from pursuing case-specific parochial interests. Elaboration of decision criteria is the more general task. Compared to a simple negotiation round, the decision situation changes in two respects. First, actors are forced to be consistent across cases. Since their 
task is limited to producing abstract standards which can be implemented by other actors, they are deprived of their opportunity to bargain over casespecific deals (Brennan and Buchanan, 1985, pp. 28-31). Even when attempting to calculate their overall interest across cases, parties will be forced to formulate a 'median preference' which can be transformed into coherent principles. Second, actors may have to decide on general criteria before becoming aware of their future case-specific preferences. Under this Rawlsian 'veil of ignorance' (Rawls, 1980, pp. 136-42), even rational utility maximizers controlling power resources will struggle for criteria which promise to produce acceptable decisions irrespective of their distributive effects. The common search for such criteria and the evaluation of the consequences of different options is a matter for discourse rather than bargaining.

Specialization on deciding single cases in light of existing decision criteria facilitates arguing because criteria limit discretion and provide standards against which decisions can be appraised. If the decisions are small and sufficiently well separated from each other, so as to preclude their linkage within explicitly negotiated packages, the typical patterns of committee governance (Sartori, 1987, pp. 227-32) emerge. The distributive effect of the single decision is usually asymmetrical and precludes a mutually acceptable bargaining outcome. Actors pursuing their case-specific interests under such conditions will inevitably jeopardize the entire co-operation project, to the effect that actors seeking to realize co-operation gains must compromise. The decision criteria provide a natural focal point that indicates in which decisions to compromise. Committee governance will be especially prone to producing criteria-based decisions if there are, besides the stakeholders, sufficient parties without stakes in the particular decision, because these neutral parties have no inherent interest in violating the criteria. Accordingly, arguments supporting the proper application of mandatory decision criteria become a powerful source of influence in the decision process.

The commitment to the sincere implementation of the decision criteria will be reinforced through an additional horizontal differentiation of the decision process. Typically, a regulatory decision consists of two components: namely the appraisal of relevant facts; and the regulatory decision made on the basis of this appraisal. The former is essentially concerned with matters of truth. Institutions can reinforce deliberative decision-making on matters of truth if they assign these issues to specialized forums (Gehring, 1999). Scientific and technological assessment panels establish a protected niche for the deliberative validation of relevant matters of truth based upon commonly shared standards for the appraisal of competing propositions. They set the agenda for the ensuing political decision process, and they provide standards for the appraisal of decisions (Krapohl, 2003). The commitment to 
the decision criteria will be further reinforced if the decision-making body is made accountable to yet another entity. The criteria provide a standard against which the decisions can be appraised. Institutionalization of the appraisal function forces decision-makers to relate their decisions explicitly to the criteria and thus provide convincing reasons ('giving reasons requirement', Shapiro, 2002). In European single market regulation, virtually all decisions are subject to potential scrutiny by the European Court of Justice (ECJ).

The changed decision-making rationales emerge from the division of labour among the sub-system involved; they are not rooted in the specificity of any of these sub-systems. Decision-making systems that separate these decision functions from each other and assign them to specialized decision processes facilitate deliberative outcomes, because they systematically reduce the ability of stakeholders to pursue their parochial interests by way of power-based bargaining. If the stakeholders' ability to bargain diminishes, or if interventions in the bargaining mode do not significantly affect the resulting regulatory decision, the most important obstacle to deliberative decisionmaking disappears. Accordingly, institutionally created incentives for deliberative decision-making will disappear if institutional opportunity structures do not readily deprive the actors of their ability to influence decisions through bargaining. At the upper level, this will especially be the case if actors can identify general preferences across cases. At the lower level it will apply if decision-makers are not effectively bound to substantive decision criteria, be it because such standards are absent or because accountability is too weak.

If this institutional arrangement creates sufficient incentives for deliberative decision-making, it will mobilize different sorts of legitimacy. On the one hand, it relies upon the political legitimacy of legislative decisions. Elaboration of general decision criteria addresses the issue of how a given sector of society ought to be regulated. This task is best performed by legislative actors that are accountable to the general public and it may include public discourse. Within the EU, it is basically a matter for the legislative procedures which involve Commission, Council and Parliament. Deliberative decision-making does not entirely rely on effective public scrutiny, because the abovementioned effects of functional specialization deprive the decision-makers as well as lobbyists and interest groups - at least partially of their bargaining opportunities. On the other hand, the institutional arrangement mobilizes the legitimacy-creating effects of expert discourse. Once it has been decided how a given sector ought to be regulated, this general decision is implemented as effectively and reasonably as possible, rather than through bargaining over specific cases. This twin foundation of legitimate regulatory decision-making is reflected in the Habermasian distinction between comparatively free political deliberation (legislation) and state administration (implementation) which 
is closely bound to law and judicial control (Habermas, 1998, chapters 4 and 7).

\section{The 'New Approach' to Single Market Regulation: Functional Differentiation and the Promise of Deliberation}

The institutional arrangement spelled out above is present in an increasing number of areas of single market regulation. The regulation of foodstuffs and the financial market, as well as the authorization of pharmaceuticals and the standardization of health and safety requirements of products result from decision-making at two separate levels. At the upper (political) level, the legislative actors, namely Commission, Council and Parliament, adopt, after consultation with interest groups, directives or regulations which spell out both substantive decision criteria and the procedures for their application. Application decisions are delegated to other bodies and the political actors refrain from intervening in lower-level processes. Moreover, in all mentioned areas of single market regulation, application decisions involve several bodies. Lower-level decisions in the foodstuffs sector are prepared and adopted by comitology committees, now upon guidance of a comparatively weak European Food Safety Authority (EFSA) (Kelemen, 2002), while the European Medical Evaluation Agency (EMEA) in fact dominates the authorization of pharmaceuticals (Gehring and Krapohl, 2007), and financial market regulation assigns an important role to a committee of competent national regulatory agencies (Moloney, 2003). Evidently, these new forms of regulation have been generally introduced to accelerate market integration and remove stalemate within the Council, not to produce more legitimate decisions.

The technical regulation of goods according to the 'New Approach' envisages particularly far-reaching delegation of decision-making competencies to private actors and may be conceived of as the prototype for functionally differentiated single market regulation (Vos, 1999, pp. 268-80). It strictly separates the elaboration of general health and safety requirements from their detailed technical specification. The legislative actors are forced to concentrate on the elaboration of general rules applicable to large product groups such as machinery or toys, rather than negotiating detailed provisions applicable to small groups of products. Technical specifications are elaborated by three privately organised European standardization organizations, namely CEN, CENELEC and ETSI, composed of the standardization organizations of the Member States (Vos, 1999, pp. 255-68). While European standards are not legally binding, Member States must assume that products conforming to 
the standards' requirements are also in conformity with the relevant directives and accept marketing of such products within their jurisdictions. Accordingly, Member States will seek to ensure that a directive's actual requirements guarantee an appropriate level of health and safety protection and that the European standards actually conform to these requirements.

European standards are adopted in a multi-step procedure that assigns functions to a number of bodies. First, a standardization project has to be mandated by the Commission after consultation of the Committee on Standards and Technical Regulations. This advisory committee constitutes the representation of the Member States. Second, standardization itself takes place within the relevant standardization body without intervention from the public actors. Third, a European standard adopted under the New Approach must be registered by the European Commission after consultation of the Committee on Standards. Fourth, a Member State doubting that a standard ensures the health and safety requirements of the relevant directive can invoke a safeguard procedure. After discussion, in the Committee on Standards, of the reasons provided, the claim is finally decided upon by the Commission. This decision is legally binding and may be brought before the European Court of Justice.

The procedure is apparently designed to bind all involved actors firmly to the legally binding criteria enshrined in the relevant directives. It draws on the technical expertise of the privately organized standardization bodies and is meant to ensure that they do not abuse their power. To preclude intergovernmental bargaining, the Committee on Standards is limited to discussion, while decisions are made by the Commission. The safeguard procedure allows contesting a badly prepared standard, while hindering the Member States from abusing their oversight rights. Finally, the Commission is not free to decide at will, because it could have to justify its decisions before the ECJ.

The New Approach to technical harmonization is widely considered to be a success. Without a doubt, it has achieved its major intention, namely accelerating harmonization and speeding up market integration (Vos, 1999, pp. 272-3). Today 23 directives, which cover wide product areas like machinery, toys, elevators or medical products, are in force. Directives are complemented by several hundred European standards.

However, it is an open question whether regulation according to the standardization procedure keeps the promise of deliberative decision-making and really mobilizes the twin pillars of legitimacy arising therefrom. Can European citizens trust in the quality of such regulation? The fact that the aforementioned 'success' is frequently attributed to the 'depoliticization' of decision-making (Nicolaidis and Egan, 2001, p. 463) may be seen as an alarm signal. Hence, should citizens fear a virtually uncontrolled technocracy? 
Answering these questions requires exploration of the day-to-day operation of the regulatory scheme. For this purpose, we examine in the following the elaboration and operation of two important directives that regulate safety of machinery and toys, respectively. While the former generally fulfils the promises of legitimate regulation, the latter points to difficulties that jeopardize legitimacy.

\section{Legitimate Technical Regulation under the Machinery Directive}

The legitimacy of technical regulation depends on the absence of opportunities of participating actors for bargaining at the two levels of decisionmaking. Under the model institutional arrangement, we can expect that the actors involved in upper (political) level decision-making are deprived of their bargaining opportunities because their task is limited to elaborating general rules applicable to a broader class of products and implemented elsewhere. Therefore, we look for open conflicts that might reflect diverging interests. Likewise, we can expect that the decision-makers of the lower (implementation) level are deprived of their bargaining power if they have clear substantive guidance and are subject to an accountability system that effectively binds them to this guidance and strictly limits the room for discrete choice. Again, we take open conflict as an indicator for divergence of interests that may reflect an attempt to bargain. We will conclude that an institutional arrangement is capable of inducing even powerful stakeholders to engage in deliberative decision-making, if we do not find opportunities for bargaining, or if bargaining attempts fail due to the limits established by the arrangement.

\section{Governance Approach and Elaboration of the Machinery Directive}

The Machinery Directive ${ }^{1}$ provides clear guidance for the subsequent elaboration of European standards. It requires machinery to be placed on the market and put into service only if, when properly installed and maintained and used for its intended purpose, it does not endanger the health or safety of persons and domestic animals or property (art. 2.1). Accordingly, every accident beyond clear misuse indicates a possible violation, although the Directive implicitly acknowledges that absolute safety cannot be attained by technical means, because some machinery is inherently dangerous. Moreover, producers are committed to taking 'the state of the art' into account when designing and constructing machinery with the purpose of approaching the objectives of the Directive (annex I, sec. 2). This is a high hurdle for

\footnotetext{
${ }^{1}$ Council Directive 89/392/EEC on the Approximation of the Laws of the Member States Relating to Machinery (OJ L 183 [1989], pp. 9-32).
} 
producers because it includes, besides the acknowledged rules for accident prevention, new findings reflected in scientific publications or new patents (Egan, 2001, p. 186). In addition, the Directive defines more specific safety requirements addressing certain risks like technical hazards, fire or explosion. Altogether, the Machinery Directive is recognised as the most sophisticated regulation of common safety requirements under the New Approach.

Legislative documents reflect surprisingly few substantive conflicts among the involved actors (Kerler, 2005a, pp. 232-40). The safety approach and its explication in general clauses and the relatively precise annexes of the Directive were easily agreed upon. Moreover, the Directive was adopted within a remarkable 18 months after submission by the Commission. Nevertheless, three conflicts are of theoretical relevance for the argument developed here. Southern countries sought exceptions from the high safety level and Denmark aimed for clauses allowing more stringent national regulation. ${ }^{2}$ These countries were able to identify specific interests across types of machinery. However, their attempts to bargain failed, because opportunistic exceptions would have jeopardized market integration based upon harmonized safety standards. Moreover, France claimed that extremely dangerous machines (e.g. for woodworking) ought to become subject to particularly high technical safety standards, while other countries, such as Germany, rejected this claim because of their training-based safety approach. Again, countries were able to infer preferences across cases and attempted to transfer their diverging domestic regulatory approaches to the European level. This conflict was difficult to settle by arguments alone. Eventually, France succeeded due to a previous decision by the ECJ that enabled it to uphold its stringent national standards. ${ }^{3}$

Legislation of the Directive confirms our expectation that the elaboration of general standards applicable to many products significantly reduces opportunities for bargaining. The few conflicts demonstrate that the Member States consider technical regulation to be highly important and meriting the pursuit of parochial interests. At stake are workers' and consumers' health and safety interests as well as the competitiveness of domestic industries. All the more remarkable are both the extremely low number of conflicts in the broad area addressed by the Directive and the mode of their settlement, especially regarding the rejection of exemptions. Hence, the participating actors in fact largely avoided bargaining and engaged in a deliberative common search for problem-adequate rules.

\footnotetext{
${ }^{2}$ Opinion of the Economic and Social Committee, OJ C 1988, 31/12/1988, p. 32; EP Report of Proceedings 24/5/1989 [2-378], p. 154; EP Report of Proceedings 15/11/1988 [2-371], pp. 98-100.

${ }^{3}$ Commission vs. French Republic, 1986, Case 8/74 ECR, p. 419.
} 


\section{Standardization under the Machinery Directive}

While the highly differentiated procedure for the elaboration of European standards is designed to foster the deliberative exchange of arguments, it cannot totally exclude bargaining among national standardization organizations. Within the most relevant body for machinery, i.e. the Comité Européen de Normalization (CEN), the initial draft of the standard is normally elaborated by a Working Group of limited size that takes into account interests of manufactures, users, consumers and standardization bodies. Draft standards are distributed to all national standardization organizations for comments. As amended in response to the comments, they are adopted by the General Assembly. A draft can be rejected by a majority of votes, but negative votes must be accompanied by reasons (see CEN, 2008). Two additional arrangements make bargaining more difficult. National standardization organizations can appeal against decisions of CEN bodies in case of a violation of CEN Internal Regulations. To avoid conflict with the public oversight actors, drafts are cross-checked, as to their compatibility with the legally binding requirements of the Directive, by a consultant.

Legitimacy concerns might emerge from the widespread inactivity of the formally established public oversight system. Formally, European standardization is under strict control by the public actors to provide additional incentives for problem-adequate standardization, and preclude unconvincing 'deals' among technical experts. However, elaborated standards are usually registered by the Commission merely upon formal control of their conformity with procedural and mandate-requirements after consultation of the Committee on Standards, whose responsibility extends to technical harmonization under all New Approach directives. Moreover, mandates for the drafting of new standards are frequently elaborated by the standardization bodies themselves and merely approved by the Commission. Hence, there is no systematic 'police-patrol' oversight (Pollack, 2003, p. 42) of every single standard. The de facto inactivity of the public actors threatens to increase the room for discrete choice during elaboration of standards by private actors.

De facto oversight relies on the safeguard procedure that may be invoked by Member States against a standard that is deemed to be incompatible with safety rules of the directive. In this case, the public actors examine in detail, especially within the Standing Committee on Machinery established under the Directive, whether the contested standard violates the requirements of the Directive. Since problem-inadequate or poorly elaborated standards will be rapidly challenged by a Member State, the standardization bodies always operate in the shadow of ex post appraisal by the public actors, and of possible 
rejection of their output. Safeguard proceedings will thus point to legitimacy deficits of the whole regulatory procedure if the underlying conflicts cannot be settled satisfactorily. The very limited number of safeguard proceedings indicates a low level of conflict between the standardization organizations and the public oversight actors. Until 2002, only ten safeguard proceedings against the altogether more than 600 standards under the Machinery Directive had been initiated by interested countries (Stefanova, 2005a, p. 271).

The evaluation of a number of critical cases that stayed on the agendas of the committees for several sessions (indicating that they were difficult to solve) demonstrates that national preferences exist, while it is almost impossible to impose a bargaining logic on the standardization process (Stefanova, 2005b). In the machinery sector, safeguard proceedings are predominantly employed to draw attention to deficits of existing standards and thus help improve the quality of existing regulation. The safeguard procedure may be invoked as a means to discipline the standardization body and accelerate an already on-going revision process. Italy drew the attention of CEN and of the public oversight actors to the fact that the European standard on silagecutters (standard EN 703) did not prevent farmers from serious injury or death when being drawn into the machine. It was able to mobilize nearconsensus against the standard (Committee on Standards, 2000b). Registration was withdrawn and a mandate for its revision adopted (OJ L 286 [2000], p. 40). Safeguard proceedings are also initiated after objections have been ignored during the standardization process. The United Kingdom drew attention to its safety concerns regarding soil-working machines that plough the soil with rotating blades to deploy seeds (standard EN 708). Contacts with parts of these machines could cause severe injury. Upon informal consultations within the Machinery Committee Directive, CEN initiated the revision of the standard.

In contrast, it is difficult to employ the procedure to promote unconvincing claims. Denmark contested a new standard on portable chainsaws for onehand use (standard EN ISO 11681-2). It claimed that the risk of severe accidents was not sufficiently abolished by technical means, but it was not able to substantiate that the risk of accidents inherent in these machines could be mitigated by additional technical requirements, and it also did not seek a total ban of the chainsaws. Although the Committee admitted that the type of machinery was extremely dangerous, the conflict was ended only by a vote after about 18 months of discussion within the two committees involved and with CEN. Ten countries present and voting supported the Commission proposal to keep the norm and request that CEN examine additional precautionary measures, while Denmark and the UK voted against it (Committee on Standards, 2000a). Although this conflict was not solved by an exchange of 
convincing arguments alone, the Committee decision reflected the most convincing proposition.

In conclusion, we did not find evidence that regulation under the Machinery Directive fails to mobilize, even in contentious cases, the sort of politically guided technocratic legitimacy that we expected to emerge from the institutional arrangement. Both the rarity of safeguard proceedings and their treatment suggest that occasional conflict contributes to improving the quality of European standards, while the standards are sufficiently well protected against unconvincing claims by Member States. Safeguard proceedings in the machinery sector are successful only if the respective initiators manage to draw attention to severe safety problems. For this purpose, they must provide extensive documentation of accidents and indicate how the problems in question might be remedied. While the actors involved do not always deliberate, as is demonstrated by the last-mentioned conflict, results reflect a deliberative rationale.

\section{Legitimacy Gaps in the Regulation of Toys}

The Toy Safety Directive constitutes a hard case for the hypothesis of institutionally induced deliberation under the New Approach, because toy safety has been subject to political tension and several publicly recognised conflicts, which reappear in the current revision process of the Directive.

\section{Governance Approach and Elaboration of the Toy Safety Directive}

The Toy Safety Directive ${ }^{4}$ provides much less reliable general guidance for standardization decision-makers than the Machinery Directive. Generally, toys shall not jeopardize the safety and/or health of users when used as intended in a foreseeable way, bearing in mind the normal behaviour of children (art. 2.1). Remaining risk must be commensurate with the ability of the users to cope with it (annex II, sec. I. 2a). Whereas the Machinery Directive is automatically adapted to technical progress through the 'state of the art' requirement, the Toy Safety Directive is not. It provides the standardization decision-makers with an increased discretion, e.g. when determining the ability of users to handle risks.

Regulatory gaps that can be attributed to divergent interests during legislation exist, especially regarding specific risks. Some well-known risks are not addressed at all by the specific safety requirements of the Directive. The

\footnotetext{
${ }^{4}$ Council Directive 88/378/EEC on the Approximation of the Laws of the Member States Concerning the Safety of Toys (OJ L 187 [1988], pp. 1-13; amended by Council Directive 93/68/EEC (OJ L 220 [1993], pp. 1-22.
} 
legislative actors deliberately side-stepped conflicts on the appropriate regulation and assigned their settlement to the standardization process. Documentation of the legislative process reveals a number of disputes about the inclusion of more specific requirements concerning particular risks, such as those originating from electrical toys, from noise, or from certain chemicals. ${ }^{5}$ Based upon their domestic regulatory approaches toward toy safety, Member States were apparently capable of identifying uniform interests on these risks across groups of toys. Moreover, countries with toy industries and the Commission struggled to avoid all too detailed regulation in order to reach rapid agreement on the Directive. In stark contrast, other risks are excessively regulated, for example, by setting exact limits for the bio-availability of non-organic chemicals like mercury, cadmium, and arsenic.

Gaps in the regulation of specific risks undermine functional differentiation between the two levels involved and have been identified as obstacles for problem-adequate regulation during the current review of the Directive. The lack of general safety requirements transfers the workload related to these risks almost entirely, i.e. without guidance beyond the general clauses, to the standardization process, and enlarges the room available for bargaining. Commission consultants pointed to these regulatory gaps (Risks and Policy Analysts Ltd., 2004, p. 42) and stakeholders generally support stricter regulation (Commission, 2007, pp. 6-7; Europe Economics, 2007).

\section{Standardization under the Toys Safety Directive}

Compared to the Machinery Directive, the Toy Safety Directive currently provides significantly more opportunities for bargaining and missing political guidance has not been systematically compensated for. Discourse theory suggests that missing decision-criteria might be elaborated within the standardization process, but this must occur separately from their application to specific cases. Whereas general A- and B-standards provide additional guidance for the development of specific C-standards in the machinery sector, standards in the toy sector are not hierarchically ordered and their number is very small. Currently, only nine toy standards are in force. ${ }^{6}$ Four of them address small groups of particularly dangerous toys (experimental sets for chemistry; other chemical toy sets; finger paints; and swings for domestic use). The rest are devoted to unspecific risks (mechanical and physical properties; flammability; migration of certain components like heavy metals; graphical symbols for age warning labelling; and safety of electric toys) and

\footnotetext{
${ }^{5}$ See, for example, Legislative Resolution of the European Parliament, OJ C 246, 9/7/1987; Opinion of the Economic and Social Committee, OJ C 323, 31/8/1987.

${ }^{6}$ OJ C 232 [2007], pp. 23-4; OJ C 56 [2006], p. 3.
} 
are valid for all kinds of toys. These standards combine general rules and very detailed provisions applicable to small groups of products. Accordingly, such standards do not exclude that packages are put together when national standardization organizations struggle to transfer their national safety concepts to the European level (Egan, 2001, p. 176).

The lasting conflict about noise from toy pistols demonstrates that lacking general guidance may lead to fierce battles among actors (Kerler, 2005b, pp. 336-47). In July 1998, CEN submitted for the first time, as part of a revised standard concerning the mechanical and physical properties of toys (EN 71-1), noise limits for toy pistols. Noise levels should not exceed $140 \mathrm{~dB}$ peak during a transitional period of three years, and $125 \mathrm{~dB}$ afterwards. Noise was to be measured at a distance of $50 \mathrm{~cm}$ from the ear, so that pistols conforming to the standard might create as much as $160 \mathrm{~dB}$ noise if fired at a distance of $5 \mathrm{~cm}$ from a child's ear. Apparently, the proposed values reflect more a bargaining compromise in light of producers' interests than a deliberative agreement on the health and safety demand of children. Germany invoked safeguard proceedings, and the Commission rejected, upon request by the Committee on Standards and the Commission's Expert Group on Toy Safety, the registration of the disputed part of the new standard. During the necessary revision process, the national standardization organizations were deeply divided on the issue. A CEN draft standard envisaging $120 \mathrm{~dB}$ was rejected by votes of the majority of member organizations. The eventually adopted standard envisages $134 \mathrm{~dB}$, i.e. the figure that just gained support by a minimum winning coalition (Fiala, 2000, p. 26). This standard was once again rejected by the public oversight actors. ${ }^{7}$ Instead, the original standard with its comparatively low limit of $125 \mathrm{~dB}$ after expiry of the transitional period was accepted, while the conformity assumption was created only after this period had expired. ${ }^{8}$ Even though the Member States and the Commission eventually thwarted the standardization body's intention to enact overly high noise limits, the finally adopted limit still reflected a bargaining compromise rather than being inferred from the Directive's safety requirements.

The conflict over softeners (phthalates) contained in baby teething rings demonstrates that the standardization apparatus, in the absence of clear guidance, may face long-term stalemate due to principled disagreement over the appropriate safety approach (Kerler, 2005b, pp. 348-56). It took CEN nearly two decades to submit the first standards on the subject in $2005^{9}$ - and registration is still pending. Due to the lasting stalemate, the problem of

\footnotetext{
${ }^{7}$ Expert Group on Toys, ENTR/TOYS/2001/027, March 9, 2001.

${ }^{8}$ See OJ L 205 [2001].

${ }^{9}$ See 'Organic Chemical Compounds - Requirements', EN 71-9; 'Sample Preparation', EN 71-10; and 'Methods of Analysis', EN 71-11.
} 
softeners in baby teething rings had to be regulated outside the Toys Safety Directive. In the absence of specific product requirement, some Member States had banned certain toys from their markets while others remained inactive. To ensure a consistent approach among all Member States, the Commission issued, under the Product Safety Directive, a ban for certain chemicals in toys that had to be renewed every three months. ${ }^{10}$ In 2005, the EU finally banned certain chemicals under an amendment to the Directive on Dangerous Substances and Preparations. ${ }^{11}$

The difficulties observed in some areas of toy safety regulation demonstrate that delegation of decision-making competencies to non-state technical experts gathered in CEN, or to experts of Member States' administrations, does not per se ensure deliberative problem-solving. If decision-makers enjoy discretion, bargaining might ensue. Accordingly, institutional stimulation of deliberation requires that technical experts receive clear guidance as to society's general acceptance of risks. The difficulties observed at the implementation level may thus be attributed to a deficient regulation at the upper (political) level. If the legislative actors side-step conflict over the general regulatory approach, they undermine the division of labour between the two levels of decision-making and remove the most important incentive for deliberation at the lower (operational) level.

\section{Conclusion}

Collectively binding decisions may be considered legitimate if they emerge from deliberation, or if they are based upon a deliberative rationale. Their legitimacy is based upon the fact that they have evolved as the most convincing solutions from discursive exchanges of reasonable arguments. To create legitimacy, a deliberation must consider all possibly convincing arguments that might have an impact on the collective decision, but it does not necessarily have to include all those possibly affected by the decision. Deliberative legitimacy will be undermined if the decision is influenced by resources other than reasonable arguments, such as threats, promises, and package deals or other forms of horsetrading. It is all too often forgotten that any assessment of the deliberative legitimacy of real-world decisions requires an analysis of whether these decisions actually reflect the deliberative rationale.

Deliberative legitimacy can arise from two different forms of deliberation that are frequently not sufficiently well separated from each other, namely political and technical deliberation. Political deliberation addresses the

${ }^{10}$ Commission Decision 815/EC, OJ L 315 [1999], pp. 46-9.

${ }^{11}$ See Directive 2005/84/EC; OJ L 344 [2005], pp. 40-3. 
broader issues of how a society wants to organize itself. It is subject to comparatively few formal restrictions and draws its legitimacy from its inclusiveness and from its transparency. Within the political system of the EU, it is relevant in the constitutional (treaty-making) and legislative processes. Technical deliberation addresses the narrower issues of how a given goal is best achieved. It is subject to much clearer guidance that stems, ideally, from political deliberation. It does not draw its legitimacy from openness and transparency, but from the competence and expertise of its (possibly only few) participants. Neither of these two forms of deliberative legitimacy is superior to the other, because they are complementary to each other. Experts cannot assume responsibility for defining the goals of society without transforming deliberative democracy into technocratic authoritarianism. Likewise, the broader public cannot assume responsibility for defining the specific safety requirements of chainsaws or for deciding upon the authorization of pharmaceuticals without creating undesired side-effects and grossly reducing the quality of regulation.

Complex decision-making arrangements can stimulate legitimate deliberative decision-making if they systematically separate the two tasks to be fulfilled in a deliberation, namely the definition of the broader lines of governance and their specification in concrete situations. Due to the demanding prerequisites, it cannot simply be assumed that powerful actors voluntarily sacrifice benefits only in order to allow problem-adequate results to emerge. To stimulate deliberative decision-making systematically, an institutional arrangement has to hinder actors from introducing their bargaining resources into the negotiation process. Separation of these two decision functions introduces a division of labour that promises to deprive stakeholders both at the political and at the technical level, partially or entirely, from their ability to bargain.

This arrangement is reflected in the New Approach to technical harmonization within the single market, which assigns the function of determining general health and safety requirements to the legislator and the function of specifying these requirements for products and groups of products to a multi-step standardization procedure. It is also present in other areas of single market policy. The regulation of the health and safety requirements for machinery in the single market demonstrates that an appropriately designed institutional arrangement can actually hinder stakeholders from bargaining. In stark contrast to the difficulties experienced with the original approach of full harmonization of limited sectors of machinery before the New Approach, legislation was almost free of conflict over specific health and safety requirements. The elaborate safety concept of the Directive provides firm guidance for the standardization process and sharply delimits 
available discretion. The analysis of some critical cases shows that the public actors involved are disciplined by the arrangement and cannot easily resort to bargaining, while the procedure provides public actors (namely the Member States) with an opportunity to effectively contest unconvincing standards.

The institutional incentives for deliberative decision-making will diminish if the division of labour between the political and the technical level fails. During the preparation of the Toy Safety Directive, the legislative actors did not manage to overcome their divergent views on all relevant issues. Some conflicts were side-stepped and left entirely to the standardization process. As a consequence, the private and public actors operating at the operational level lack guidance. Their discretion is not as clearly delimited as necessary, and the mechanism of functional differentiation has not become as effective as in the field of machinery. In line with our theoretical expectation, bargaining is therefore more easily reintroduced into the decision process, because stakeholders are able to define their parochial interests and dispose of the necessary discretion to choose regulation largely unguided by mandatory decision criteria.

\section{Correspondence:}

Thomas Gehring

Otto-Friedrich-University of Bamberg

Feldkirchenstr. 21

96045 Bamberg

e-mail: thomas.gehring@uni-bamberg.de

\section{References}

Brennan, G. and Buchanan, J. (1985) The Reason of Rules. Constitutional Political Economy (Cambridge: Cambridge University Press).

CEN (2008) 'Internal Regulations. Part 2: Common Rules for Standardization Work'. Available at «www.cen.eu/boss/supporting/reference+documents/2008internal regulationpart2englishfinal.pdf».

Cohen, J. and Sabel, C.F. (1997) 'Directly-Deliberative Polyarchy'. European Law Journal, Vol. 3, No. 4, pp. 313-42.

Commission (2007) 'Public Consultation on "Revision of Toys Safety Legislation". Comments provided on behalf of organizations, institutions or enterprises'. Available at: «http://ec.europa.eu/enterprise/toys/public_consultation.htm».

Committee on Standards (2000a) 'Report of the 82nd Session of the Committee on Standards and Technical Regulations of March 15, 2000'.

Committee on Standards (2000b) 'Report of the $84^{\text {th }}$ Session of the Committee on Standards and Technical Regulations of 12/10/2000'. 
De la Porte, C. and Nanz, P. (2004) 'The OMC: A Deliberative Democratic Mode of Governance? The Cases of Employment and Pensions'. Journal of European Public Policy, Vol. 11, No. 2, pp. 276-88.

Egan, M. P. (2001) Constructing a European Market. Standards, Regulation, and Governance (Oxford: Oxford University Press).

Elgström, O. and Jönsson, C. (2000) 'Negotiation in the European Union: Bargaining or Problem-solving?' Journal of European Public Policy, Vol. 7, No. 5, pp. 684-704.

Elster, J. (1989) The Cement of Society. A Study of Social Order (Cambridge: Cambridge University Press).

Elster, J. (1998) 'Deliberation and Constitution Making'. In Elster, J. (ed.) Deliberative Democracy (Cambridge: Cambridge University Press).

Eriksen, E.O. and Weigård, J. (1997) 'Conceptualizing Politics. Strategic or Communicative Action'. Scandinavian Political Studies, Vol. 20, No. 3, pp. $219-41$.

Eriksen, E.O. and Fossum, J.O. (2002) 'Democracy through Strong Publics in the European Union?' JCMS, Vol. 40, No. 3, pp. 401-24.

Europe Economics (2007) 'Revision of the Chemical Requirements of Directive 88/378/EEC on the Safety of Toys'. Available at: «http://ec.europa.eu/enterprise/ toys/public_consultation.htm».

Fiala, F. (2000) 'Toys and Noise: Standardization Committee Still Refuses Adequate Limits'. Consumer Voice, special edition 2000, pp. 25-6.

Follesdal, A. and Hix, S. (2006) 'Why there is a Democratic Deficit in the EU: A Response to Majone and Moravcsik'. JCMS, Vol. 44, No. 3, pp. 533-62.

Gehring, T. (1999) 'Arguing, Bargaining and Functional Differentiation of Decisionmaking. The Role of Committees in European Environmental Process Regulation'. In Joerges, C. and Vos, E. (eds) EU Committees. Social Regulation, Law and Politics (Oxford: Hart).

Gehring, T. (2003) 'Communicative Rationality in European Governance? Interests and Communicative Action in Functionally Differentiated Single Market Regulation'. In Eriksen, E.O., Joerges, C. and Neyer J. (eds) European Governance, Deliberation and the Quest for Democratization. Arena Report, No. 2 (Oslo: Arena).

Gehring, T. and Krapohl, S. (2007) 'Supranational Regulatory Agencies between Independence and Control. The EMEA and the Authorization of Pharmaceuticals in the European Single Market'. Journal of European Public Policy, Vol. 14, No. 2, pp. 208-26.

Habermas, J. (1984) Theory of Communicative Action, Vol. 1: Reasons and the Rationalization of Society (Boston: Beacon).

Habermas, J. (1998) Between Facts and Norms. Contributions to a Theory of Law and Democracy (Cambridge: MIT Press).

Hix, S., Noury, A. and Roland, G. (2005) 'Power to the Parties: Cohesion and Competition in the European Parliament, 1979-2001'. British Journal of Political Science, Vol. 35, No. 2, pp. 209-34. 
Joerges, C. and Neyer J. (1997) 'From Intergovernmental Bargaining to Deliberative Political Processes. The Constitutionalization of Comitology'. European Law Journal, Vol. 3, No. 3, pp. 273-99.

Joerges, C. (1999) “ "Good Governance” through Comitology?' In Joerges, C. and Vos, E. (eds) EU Committees. Social Regulation, Law and Politics (Oxford: Hart).

Joerges, C. (2006) 'Deliberative Political Processes Revisited: What Have We Learnt About the Legitimacy of Supranational Decision-Making?' JCMS, Vol. 44, No. 4, pp. 779-802.

Kelemen, R. D. (2002) "The Politics of "Eurocratic" Structure and the New European Agencies'. West European Politics, Vol. 25, No. 4, pp. 93-118.

Kerler, M. (2005a) 'Die Maschinenrichtlinie: Begrenzter Einfluß nationaler Interessen unter dem Schleier des Nichtwissens'. In Gehring, T., Krapohl, S., Kerler, M. and Stefanova, S. (eds) Rationalität durch Verfahren in der Europäischen Union. Europäische Arzneimittelzulassung und Normung technischer Güter (BadenBaden: Nomos), pp. 223-45.

Kerler, M. (2005b): 'Der Umgang mit Problemfällen in der Spielzeugregulierung'. In Gehring, T., Krapohl, S., Kerler, M. and Stefanova, S. Rationalität durch Verfahren in der Europäischen Union. Europäische Arzneimittelzulassung und Normung technischer Güter (Baden-Baden: Nomos), pp. 335-58.

Kohler-Koch, B. and Rittberger, B. (2007) 'Charting Crowded Territory'. In KohlerKoch, B. and Rittberger, B. (eds) Debating the Democratic Legitimacy of the European Union (Plymouth: Rowman \& Littlefield), pp.1-29.

Krapohl, S. (2003) 'Risk Regulation in the EU Between Interests and Expertise. The Case of BSE'. Journal of European Public Policy, Vol. 10, No. 2, pp. 189-207.

Lord, C. and Magnette, P. (2004) 'E Pluribus Unum? Creative Disagreement about Legitimacy in the EU'. JCMS, Vol. 42, No. 1, pp. 183-202.

Lord, C. and Beetham, D. (2001) 'Legitimizing the EU. Is there a "Postparliamentary Basis" for its Legitimation?' JCMS, Vol. 39, No. 3, pp. 44362.

Majone, G. (1996) Regulating Europe (London: Routledge).

Majone, G. (2001) 'Two Logics of Delegation. Agency and Fiduciary Relations in EU Governance'. European Union Politics, Vol. 2, No. 1, pp. 103-21.

Moloney, N. (2003) 'The Lamfalussy Legislative Model. A New Era for the EC Securities and Investment Services Regime'. International and Comparative Law Quarterly, Vol. 52, No. 2, pp. 509-20.

Moravcsik, A. (2002) 'In Defence of the "Democratic Deficit". Reassessing Legitimacy in the European Union'. JCMS, Vol. 40, No. 4, pp. 503-24.

Murphy, M. (2005) 'Between Facts, Norms, and a Post-national Constellation: Habermas, Law and European Social Policy'. Journal of European Public Policy, Vol. 12, No. 1, pp. 143-56.

Neyer, J. (2003) 'Discourse and Order in the EU: A Deliberative Approach to Multi-level Governance'. JCMS, Vol. 41, No. 4, pp. 687-706. 
Nicolaidis, K. and Egan, M. (2001) 'Transnational Market Governance and Regional Policy Externality. Why Recognize Foreign Standards?' Journal of European Public Policy, Vol. 8, No. 3, pp. 454-73.

Pollack, M. A. (2003) The Engines of European Integration: Delegation, Agency, and Agenda-Setting in the EU (Oxford: Oxford University Press).

Rawls, J. (1980) A Theory of Justice (Cambridge: Harvard University Press).

Risks \& Policy Analysts Ltd. (2004) 'Study on the Impact of the Council Directive 88/378/EEC on the Safety of Toys. Final Report Prepared for the European Commission'. Available at: «http://ec.europa.eu/enterprise/toys/public_ consultation.htm».

Risse, T. (2000) ' "Let's Argue!” Communicative Action in World Politics'. International Organization, Vol. 54, No. 1, pp. 1-39.

Sartori, G. (1987) The Theory of Democracy Revisited (Chatham, NJ: Chatham House).

Shapiro, M. (2002) 'The Giving-Reasons Requirement'. In Shapiro, M. and Stone Sweet, A. (eds) On Law, Politics, and Judicialization (Oxford: Oxford University Press).

Scharpf, F. W. (1997) Games Real Actors Play. Actor-centred Institutionalism in Policy Research (Boulder, CO: Westview).

Stefanova, S. (2005a) 'Die Umsetzung der Maschinenrichtlinie'. In Gehring, T., Krapohl, S., Kerler, M. and Stefanova, S. (eds) Rationalität durch Verfahren in der Europäischen Union. Europäische Arzneimittelzulassung und Normung technischer Güter (Baden-Baden: Nomos).

Stefanova, S. (2005b): 'Problemfälle bei der Umsetzung der Maschinenrichtlinie'. In Gehring, T., Krapohl, S., Kerler, M. and Stefanova, S. (eds) Rationalität durch Verfahren in der Europäischen Union. Europäische Arzneimittelzulassung und Normung technischer Güter (Baden-Baden: Nomos).

Vos, E. (1999) Institutional Frameworks of Community Health and Safety Legislation. Committees, Agencies and Private Bodies (Oxford: Hart). 